\title{
Eosinophilic cellulitis (Wells' syndrome) caused by a temporary henna tattoo
}

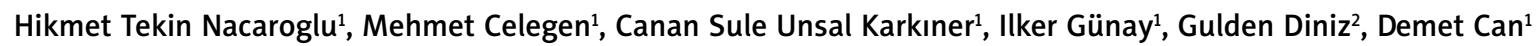

${ }^{1}$ Department of Pediatric Allergy, Dr Behcet Uz Children's Hospital, Izmir, Turkey

Head of Department: Demet Can Assoc. Prof., MD

${ }^{2}$ Department of Pediatric Pathology, Dr Behcet Uz Children's Hospital, Izmir, Turkey

Head of Department: Gulden Diniz Assoc. Prof., MD

Postep Derm Alergol 2014; XXXI, 5: 322-324

DOI: 10.5114/pdia.2014.40951

\begin{abstract}
Eosinophilic cellulitis (Wells' syndrome) is an uncommon condition of unknown etiology. Wells' syndrome is usually seen in adulthood but very rare in childhood. Although pathogenesis of the disease is not very clear, it is a hypersensitivity reaction developing against a variety of exogenous and endogenous antigenic stimuli. Paraphenylenediamine is a strong allergen frequently used as a temporary henna tattoo, which makes the color darker. Here, a 9-year-old male patient with Wells' syndrome is presented, which developed following a temporary henna tattoo and shown by the patch test sensitivity to paraphenylenediamine.
\end{abstract}

Key words: eosinophilic cellulitis, Wells' syndrome, paraphenylenediamine, henna tattoo.

\section{Introduction}

In recent years, temporary henna tattoo has become popular among teenagers. Various substances are added to temporary henna tattoo dye to ensure the formation of black color and accelerate the absorption of dye by the skin. Paraphenylenediaine (PPD) is frequently used for this purpose and can cause a variety of allergic and hypersensitivity reactions, especially irritant contact dermatitis [1]. Wells' syndrome is an uncommon inflammatory dermatosis of unknown etiology, with few cases reported worldwide. Wells' syndrome is characterized by a pruritic rash, which usually follows a relapsing and remitting course, and distinct histology showing an infiltrate of eosinophils within the dermis. Seven clinical variants of Wells' syndrome have been documented: plaque type, annular granuloma-like, urticaria-like, papulovesicular, bullous, papulonodular and fixed drug eruption-like [2-4]. Hypersensitivity response to a circulating antigen and an abnormal eosinophilic response to a number of causative agents are thought to be the cause [3, 5].

Here, a case of Wells' syndrome developed following paraphenylenediamine application is reported.

\section{Case report}

A 9-year-old male patient suffered from redness and itching on the tattoo area 3 days after the application of a temporary tattoo. Systemic antihistamines and topical steroids were started and used for 10 days. The patient was admitted to our clinic because of lesions spread to the whole body. In his medical history, there was no atopic and chronic disease, prior to the eruption, there were no insect bites, or viral, bacterial and parasitic infection. Physical examination revealed erythematous, edematous, and papulonodular lesions on the left arm, the area of tattoo henna. Similar lesions were also seen on the trunk, spine and extremities (Figures 1 and 2). Examinations of other systems were normal. Laboratory examination was unremarkable, except mild eosinophilia $\left(7 \%\right.$ Eo, 600/ $\left.\mathrm{mm}^{3}\right)$. Routine biochemical tests were within normal limits. Punch biopsy from tattoo area revealed superficial type hyperkeratosis irregular acanthosis in the epidermis; an inflammatory reaction accompanied by polymorphonuclear leukocyte, eosinophils and histiocytic infiltration in the dermis around the blood vessel walls, eccrine glands and hair follicles. In one area of the dermis, flame figures and around these figures, histiocytic cells were seen (Figure 3).

The patient was diagnosed as Well's syndrome with clinical and histopathological findings. Lesions resolved without sequelae within 10 days of short-term systemic corticosteroid therapy. A patch test was done with standard "ALK T.R.U.E" test series after clinical improvement after 6 weeks. Paraphenylenediamine and Black Rubber

Address for correspondence: Hikmet Tekin Nacaroglu, Department of Pediatric Allergy, Dr Behcet Uz Children's Hospital, Izmir, Turkey, phone: +90 23241163 19, fax: +90 23248923 15, e-mail: tekin212@gmail.com Received: 11.11.2013, accepted: 20.11.2013. 


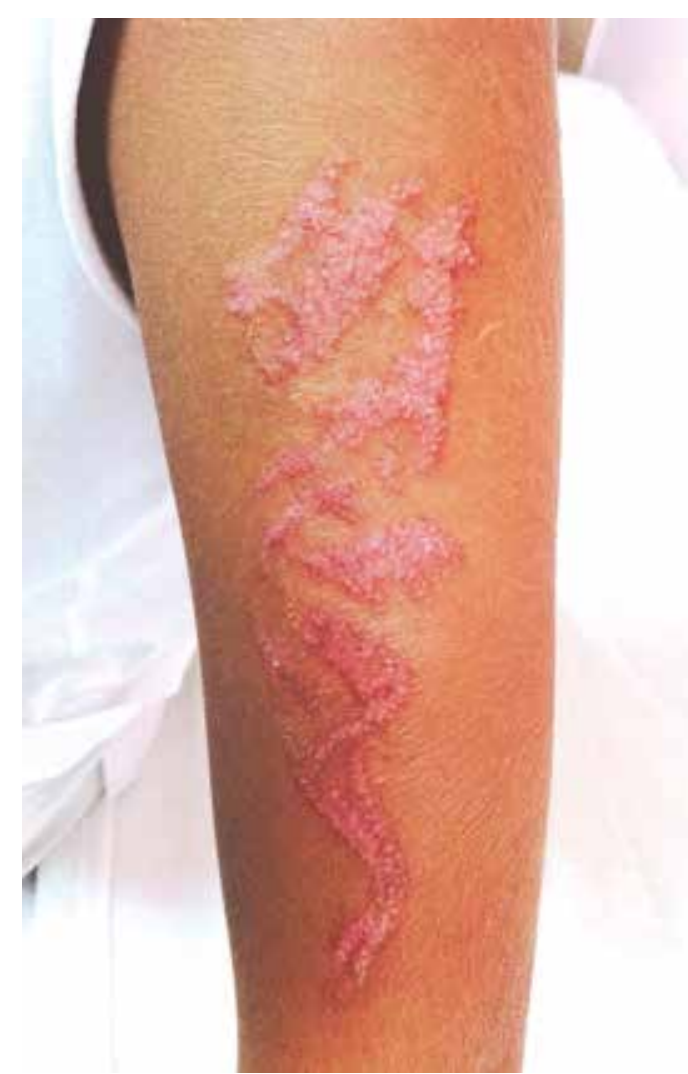

Figure 1. Erythematous, edematous, papulonodular lesions on the tattoo area

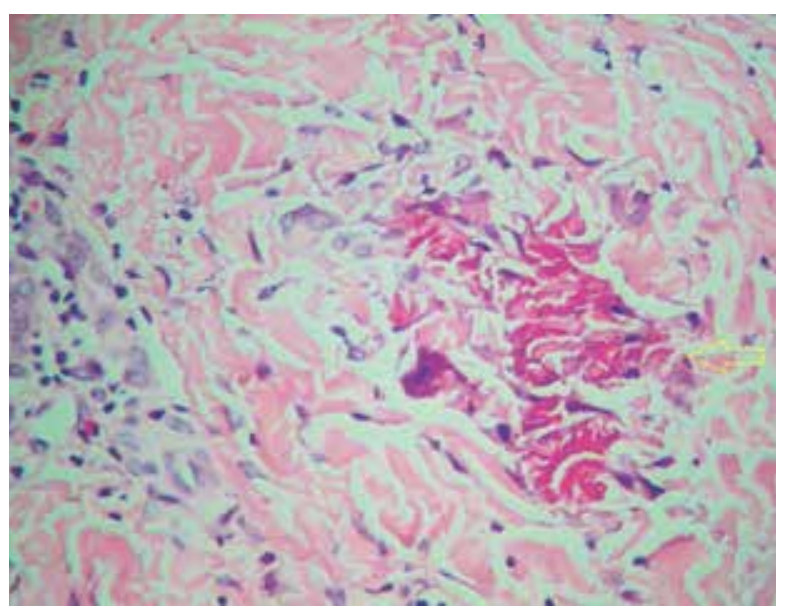

Figure 3. Eosinophilic granular formation defined as a flame figure in dermis $(H+E 400 x)$

Mix $3+$ induration was developed at 48,72 and $96 \mathrm{~h}$ (Figure 4).

\section{Discussion}

George Wells first described this syndrome in 1971 as a 'recurrent granulomatous dermatitis with eosinophilia'.

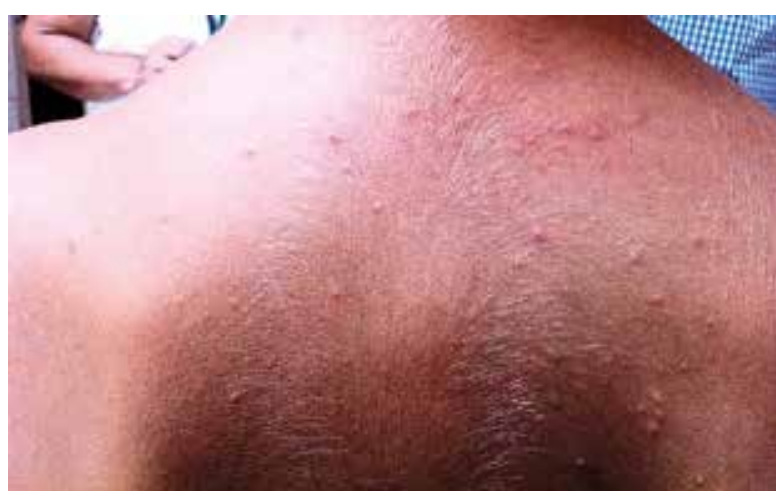

Figure 2. Erythematous, edematous papules on the back

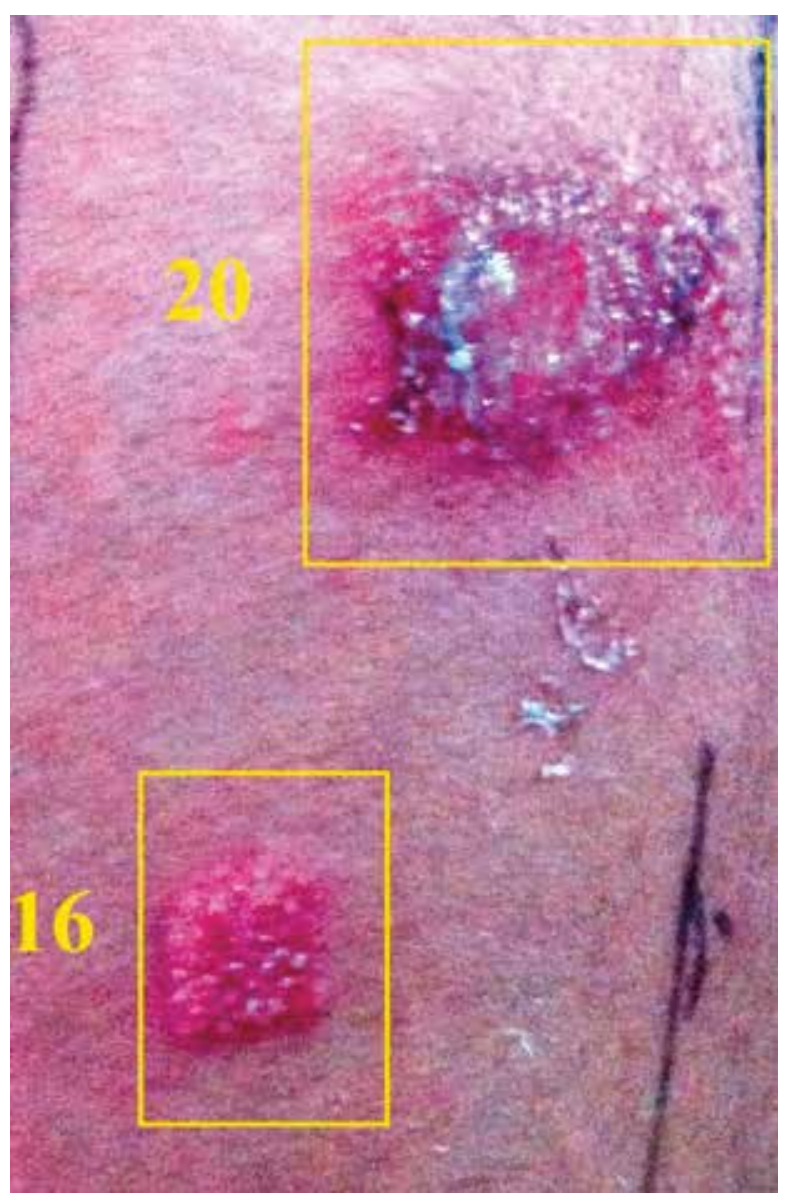

Figure 4. Positive patch test reaction to black rubber mix (16) and paraphenylenediamine (20) in $48 \mathrm{~h}$

In 1979, it was referred to as "eosinophilic cellulitis" by Wells and Smith [2-5]. Lesions mostly localized on the limbs or trunk, with a sudden onset of itching and burning sensation, local temperature increase is usually not present, and it is in the form of one or more erythematous plaques and does not respond to antimicrobial treatment. Pruritus can be intractable and unresponsive 
to anti-histamines. Affected individuals typically present with erythematous plaques over a 2- to 3-day period and plaques usually resolve without scarring over 2-8 weeks [6]. During this period, pale and atrophic skin lesions may be confused with symptoms of morphea disease [3-6]. In our case, papulonodular and papular lesions were seen on the back and limbs, apart from the tattoo region. Wells' syndrome is rarely present with systemic involvement, but eosinophilia is common [7]. Peripheral eosinophilia was found in half of the cases as well as in our patient, but it is not required for diagnosis $[6,7]$.

The pathophysiology of the lesions in Wells' syndrome remains unknown. It has been suggested that excess production of IL-5 occurs, which drives eosinophilic accumulation in a local Th2 immune response [8]. There was no etiological reason in approximately half of the cases reported in the literature [5-8]. Arthropod, insect bites, drugs, myeloproliferative disorders, viral, bacterial and parasitic infections are shown as triggering factors. Penicillins, lincomycin, tetracycline, minocycline, ampicillin, erythromycin, bleomycin, chlorambucil, anticholinergics, anesthetics, danazol, acetylsalicylic acid, tenoxicam, diclofenac sodium and amoxicillin are drugs which have been reported to trigger Wells' syndrome [3, 5-8]. Thiomersal is used as a preservative in vaccines, and Wells' syndrome cases caused by thiomersal have been reported and the sensitivity shown by the patch test [9]. As in our case, type 4 hypersensitivity reaction plays a role in the etiology of Wells' syndrome when the sensitivity of the patch test is shown [9].

There are three histopathologic stages - edema and eosinophilic infiltration of the dermis are seen in acute stage, subacute stage is characterized by eosinophils and flame figures, consisting of histiocytic and the healing stage when a group of foreign body giant cells forms microgranulomas [3, 7-9]. The histopathologic findings are characterized by flame figures, which are composed of eosinophil major basic protein deposited on collagen bundles that was found in our case but was not specific [3, 7-10]. The papulonodular form, a rare form of Wells' syndrome, is considered with clinical and histological findings in our case. In the series of 19 pediatric patients, the classic plaque-type variant proved to be the most common presentation in children but not in adults, who more frequently had the annular granuloma-like variant. The course was recurrent, although slowly progressing, with a mean duration of disease of 5 years for adults and 3 years for children [5].

Low-dose oral corticosteroids are the first-line treatment in Wells' syndrome. Other treatment options are topical corticosteroids, antihistamines, anti-microbial agents, dapsone, griseofulvin, colchicine, cyclosporine, azathioprine, interferon $\alpha$, and ultraviolet light [3, 5, 9, 10]. In our case, clinical improvement was observed with the short-term $40 \mathrm{mg} /$ day of oral corticosteroid therapy.
In the literature, approximately 30 children with Wells' syndrome have been reported [10]. However, no sensitivity of paraphenylenediamine was observed in any of the cases. Our patient is the first pediatric case of Wells' syndrome which developed after the application of temporary henna tattoos, and sensitization to paraphenylenediamine is shown by the patch test. Recently, the use of temporary tattoos has become widespread in children and young people, but the society is uninformed about the potential consequences of temporary tattoos. It should be emphasized that it is not a harmless application.

\section{References}

1. Jovanovic DL, Slavkovic-Jovanic MR. Allergic contact dermatitis from temporary henna tattoo. J Dermatol 2009; 36: 63-5.

2. Wells GC. Recurrent granulomatous dermatitis with eosinophilia. Trans St Johns Hosp Dermatol Soc 1971; 57: 46-56.

3. Gilliam AE, Bruckner AL, Howard RM, et al. Bullous "cellulitis" with eosinophilia: case report and review of Wells' syndrome in childhood. Pediatrics 2005; 116: 149-55.

4. Tugnet N, Youssef A, Whallett AJ. Wells' syndrome (eosinophilic cellulitis) secondary to infliximab. Rheumatology 2012; 51: 195-6.

5. Caputo R, Marzano AV, Vezzoli P, et al. Wells' syndrome in adults and children a report of 19 cases. Arch Dermatol 2006; 142: 1157-61.

6. Green WH. Recurrent, pruritic dermal plaques and bullae. Arch Dermatol 2007; 146: 791-6.

7. Carlesimo M, Fidanza L, Mari E, et al. Wells' syndrome with multiorgan involvement mimicking hypereosinophilic syndrome. Case Rep Dermatol 2009; 1: 44-8.

8. French LE, Shapiro M, Junkins Hopkins JM, et al. Eosinophilic fasciitis and eosinophilic cellulitis in a patient with abnormal circulating clonal T cells: increased production of interleukin 5 and inhibition by interferon alfa. J Am Acad Dermatol 2003; 49: 1170-4.

9. Koh KJ, Warren L, Moore L, et al. Wells' syndrome following thiomersal-containing vaccinations. Australas J Dermatol 2003; 44: 199-202.

10. Cherng E, McClung AA, Rosenthal HM, et al. Wells' syndrome associated with parvovirus in a 5 -year old boy. Pediatr Dermatol 2011; 9: 1-3. 